\title{
Discurso na posse da nova Diretoria*
}

\author{
Marcia Angela Aguiar \\ Presidente da Associação Nacional de Pós-Graduação e Pesquisa em Educação (ANPEd)
}

Ilustríssimas autoridades. Caríssimos associados da ANPEd.

Com intensa alegria e muita emoção compareço a esta solenidade em que serei, junto com valorosos e valiosos companheiros e companheiras, forjados nas lides e lutas acadêmico-científicas, e portanto políticas, revestida com a honraria de assumir a presidência da Associação Nacional de Pós-Graduação e Pesquisa em Educação (ANPEd) para o biênio 2005-2007, por escolha livre e soberana de expressivo contingente dos que fazem esta entidade.

Dizia o poeta que devemos saber viver o sabor do nosso tempo... Ao me debruçar na redação destas palavras, quedei-me silenciosa por um bom tempo e deixei que as lembranças e recordações, tais quais ondas que beijam as areias da praia, assomassem à memória, trazendo lances de minha trajetória acadêmica e política, ao longo de duas décadas, que reconheço entrelaçada e em boa parte tributária da construção acadêmico-político do coletivo chamado ANPEd.

${ }^{*}$ Proferido no Rio de Janeiro, em 9 de dezembro de 2005.
Dou-me a licença (se tivesse o dom, poética!), neste momento de emoção, de reportar-me ao ano de 1984, quando estudante que era, adentrei, pela primeira vez, no espaço da ANPEd. Ao fazê-lo descobri estar ingressando em um dos mundos privilegiados da academia, considerando a dura realidade educacional do país de milhões analfabetos. Flashes daquele momento ressurgem com nitidez! Vêm à mente os rostos juvenis, apaixonados e decididos de acadêmicos, os quais em sua maioria nunca vira antes, que debatiam, com veemência, problemas da educação nacional, particularmente da pesquisa e da pós-graduação. Atentamente, ouvia, serem pronunciados os seus respectivos nomes, e começava a me sentir muito à vontade: todos aqueles intelectuais eram velhos conhecidos nas lides do curso de mestrado.

Naquela manhã de sol de setembro, em uma sala da Faculdade de Educação da Universidade de Brasília - universidade sonhada por Darcy Ribeiro -, alternavam-se as vozes, em meio à acalorada discussão, desses intelectuais engajados na luta pela redemocratização do país (alguns dentre eles presentes nesta solenidade!). Fiquei fascinada com aquele debate e, 
depois daquela primeira reunião, vieram outras e tantas outras... que na minha vida já totalizam vinte e quatro, às quais sempre me refiro, revelando aos meus estudantes da pós-graduação, com orgulho, nunca ter faltado a uma sequer.

Aos poucos, fui conquistada pela magia do compromisso com a crescente qualificação da pós-graduação em educação nas universidades públicas e vi surgir, a cada reunião anual, novos atores, de todas as regiões do país, que encontravam na ANPEd o espaço para o exercício da crítica e da criatividade.

Vi (e vivi!) a ANPEd como o intelectual coletivo de sabor gramsciano: espaço aglutinador das diferenças e dos diferentes, arena de disputas filosófico-políticas, construtoras ou desmistificadoras de propostas de natureza diversas que circulam no território educacional. Espaço de ressonância das questões polêmicas do nosso tempo atinentes ao campo das idéias e às práticas da sociedade brasileira no contexto das relações globalizadas. E, nesse espaço, não foram poucas as lutas das quais participei. Sempre por uma boa causa: a defesa intransigente da democracia e da educação pública, laica, republicana para todos e todas!

No início, frequientavam a ANPEd poucos estudantes da pós-graduação, tímidos naquele momento, mas, transcorridos dez ou vinte anos, tornaram-se exemplos de maturidade intelectual como bem o demonstra alguns integrantes de nossa Diretoria.

Vi até mesmo personagens desse universo se transmutarem em estrelas que cintilam mais brilhantes, em noite de lua cheia, quando escutam, no silêncio infinito, o eco das nossas vozes as chamando pelos respectivos nomes: Neidson Rodrigues! Presente... Maurício Tragtenberg! Presente... Joel Martins! Presente...

Muita coisa aprendi, ao longo do tempo, na convivência com esses mestres eméritos: acatando, questionando, duvidando, contestando, incorporando, me contrapondo. Mas, refletindo sempre, sempre querendo saber mais.

Com a ANPEd, todos nós aprendemos a construir a travessia democrática que desembocou nas lutas da Constituinte e da Lei de Diretrizes e Bases da Educação Nacional. Que o digam aqueles que parti- cipavam incansavelmente do "corpo a corpo" no Congresso Nacional, no esforço de convencer deputados e senadores que a sociedade exigia respostas imediatas para os problemas educacionais. Nas concorridas Conferências Brasileiras de Educação, nossas CBEs, cuja organização tinha, também, o protagonismo e a pujança da ANPEd refletida nas conferências, palestras e grupos de estudo, despertando e mobilizando corações e mentes de jovens estudantes em auditórios e salas lotadas dos campi das universidades nas quais foram realizadas.

Na CBE de Goiânia, acorremos ao Ginásio de Esportes, para ocupar um lugar e aplaudir entusiasticamente a argumentação brilhante e contundente de Miriam Limoeiro Cardoso, numa tarde de debate inesquecível, nos idos de 1980, quando as divergências teóricas e políticas começavam a demarcar o terreno das esquerdas, derrubando os consensos construídos na luta contra o regime autoritário, prenúncio do que viria a se expressar no campo da política na nascente democracia brasileira.

$\mathrm{Na} \mathrm{CBE}$ de Brasília, lotamos o auditório do Palácio das Artes, para anunciar novos tempos para a educação brasileira, ovacionando a palavra de Octavio Elisio ao relatar que dera entrada, na Câmara Federal, ao projeto das novas Diretrizes e Bases da Educação Nacional, com o registro inicial de Dermeval Saviani.

Como ANPEd, participamos ativamente da construção do Plano Nacional de Educação (PNE), como membro do Fórum Nacional em Defesa da Escola Pública, do qual fizemos uma tribuna para influir na formulação das políticas públicas em prol da educação nacional, contrapondo-nos aos vetos presidenciais, que subestimavam as demandas educacionais.

Como ANPEd, enfrentamos também o debate teórico, epistemológico e metodológico motivado pela crise paradigmática que aportou em nossas plagas, traduzida na diversificação da produção da área das ciências humanas e sociais. Fomos capazes de resistir aos acenos daqueles que apregoavam o fim da história e das ideologias, denunciando permanentemente e com competência, porque assentada em consistente 
produção teórica, as falsas premissas da suposta vitória do capitalismo, como sistema ideal para a humanidade. Não nos abatemos: ao contrário, avivamos a nossa capacidade crítica, quando a onda do neoliberalismo pretendeu varrer da história o legado dos clássicos que nos ensinaram a pôr o homem no centro da produção material. Nesse movimento, a ANPEd foi uma das primeiras a contrapor-se a essas idéias e a alertar para os riscos da visão que queria impor, a todos, o mercado como a única saída.

Pugnamos por políticas públicas estruturadoras que revelem o Estado não como mínimo ou máximo, mas o Estado que cumpra suas finalidades como garantidor e regulador de relações sociais justas e igualitárias em um país com enormes distâncias econômicas, que se traduzem na escandalosa concentração de renda e revelam-se na vida das populações empobrecidas e miseráveis, numa sociedade em que a violência explode no cotidiano.

A ANPEd dá guarida, nos grupos de pesquisa, às letras do alfabeto da diversidade e do pluralismo, reiterando a idéia da igualdade, tão cara, desde os gregos atenienses, passando pela Revolução Francesa, no sentido que nos fala Santos (1995): "lutar pela igualdade sempre que as diferenças nos discriminem. Lutar pelas diferenças sempre que a igualdade nos descaracterize".

Nos últimos tempos, a ANPEd viu adentrar, em suas reuniões anuais, levas e levas de jovens estudantes da pós-graduação, que se espelham em seus mestres para praticar com eles as questões fundamentais da pesquisa, no delineamento das problemáticas que os impulsionam na busca de quadros referenciais teóricometodológicos que possam iluminar melhor os caminhos para as descobertas e invenções que beneficiem a sociedade como um todo e, particularmente, as camadas espoliadas da população brasileira.

Pautando sua trajetória na ética, enfrenta a ANPEd os novos tempos que mostram o Brasil com o que há de mais moderno no mundo contemporâneo ao lado de paisagens que lembram os piores quadros do mundo medieval. Nesse cenário, enfrenta os desafios do presente e do futuro sem abrir mão do ques- tionamento permanente do instituído e dado como verdade imutável. Suas armas: o ideário humanista e os instrumentais teórico-analíticos, fruto do esforço intelectual do coletivo dos pesquisadores que a constitui.

$\mathrm{Na}$ atualidade, a ANPEd enfrenta grandes desafios: manter sua autonomia, sem se fechar no seu mundo interno; conviver com o príncipe sem subserviência ou arrogância; criticar as políticas e iniciativas do poder público, sem preconceitos nem dogmatismos; defender, nos fóruns próprios, a produção científica sem se deixar levar pelas leis do mercado; ser suficientemente aberta aos novos avanços decorrentes da pesquisa científica e da criação humana.

Desafio de manter-se fiel à tradição dos clássicos; inquieta em busca de novos sentidos, como os jovens; lúcida na capacidade de análise e da crítica, como os veneráveis sábios; com a coragem de intervir, no momento necessário, nas questões prementes e essenciais da educação nacional.

Na construção permanente dessa ANPEd, que, ao longo dos seus 28 anos de existência construiu e consolidou trajetória de destacada prática acadêmica e de corajosa luta política, alguns têm a honra e o encargo de assumir, periodicamente, o leme deste barco que singra mares (às vezes calmos, outras vezes com ondas altas), respaldados pela corrente marítima do grande coletivo que se espalha nos programas da pós-graduação e nas instituições de pesquisa deste país-continente.

Neste exato momento, somos o grupo que assume este leme, com a responsabilidade histórica de singrar os mares com coragem e coerência, observando os pontos-chave do mapa que se traduziu em nossa carta-programa, cujo ponto de maior expressão é o de contribuir com a entidade no fortalecimento da formação pós-graduada em educação, na promoção do profícuo debate entre pesquisadores e no firme apoio aos programas de pós-graduação.

Dentre os inúmeros desafios, a Diretoria que hoje assume a ANPEd, escolheu alguns para serem enfrentados, buscando conferir centralidade aos grandes temas da educação nacional de modo a intervir de forma mais incisiva (crítica e propositiva) na formulação das políti- 
cas públicas que incidem no campo da educação. Assim, neste momento reafirma os compromissos já manifestos, de atuar no sentido de contribuir para o fortalecimento da pós-graduação e da pesquisa em educação, com o ensino de qualidade para todos e com uma escola comprometida com os interesses da maioria da população, que faça, da passagem por ela, processo revigorado de cidadania e prática social.

Nessa perspectiva, compromete se a apoiar iniciativas regionais, contemplando as especificidades locais, incentivando o fortalecimento dos programas de pós-graduação em educação e a elevação dos padrões da produção acadêmica, sem, no entanto, deixar de levar em conta que o regional e o local fazem parte de uma totalidade nacional e internacional. Com igual entusiasmo, buscará ampliar a participação da ANPEd nos debates referentes aos contextos político-econômico e educacional nacional e internacional, bem como nos processos decisórios sobre políticas públicas em educação, nas diferentes instâncias e órgãos governamentais. Nessa direção, comprometese a debater e subsidiar a construção de propostas de políticas educacionais e sua avaliação, especialmente as voltadas para a educação pública e para seu financiamento, fundamentando-se na produção científico-tecnológica da área e no compromisso com a democratização substantiva da sociedade. Buscará ampliar os canais de participação na definição das políticas de ciência e tecnologia, especialmente as comprometidas com o equacionamento e a solução dos problemas que afetam a maioria da população brasileira. Compromete-se a ampliar a articulação e o intercâmbio com as sociedades e entidades científicas de outras áreas do conhecimento, visando a fortalecer a pós-graduação e a pesquisa em educação no enfrentamento das questões comuns à comunidade acadêmica brasileira, especialmente aquelas relacionadas às políticas educacionais e de ciência e tecnologia. Considera relevante fortalecer os canais de intercâmbio e de articulação com a comunidade científica nacional e internacional e com os movimentos sociais, tendo em vista o debate e a construção de alternativas ao modelo de globalização hoje hegemô- nico, com profundos reflexos negativos sobre as camadas majoritárias da população do país.

À Diretoria que nos entrega o leme da entidade, representada na pessoa da professora Betania Leite Ramalho, somente palavras de reconhecimento pelo trabalho realizado nos últimos dois anos, pelo cumprimento das metas estabelecidas, pela condução democrática da entidade e, particularmente, pela postura acadêmica na direção do processo eleitoral e no período de transição da gestão.

Aos amigos e companheiros da Diretoria que hoje, nesta cerimônia, assumem comigo a direção da ANPEd, algumas palavras: que sejamos, nas pequenas e grandes tarefas da entidade, dignos da confiança de que somos depositários; dedicados na execução das tarefas que vêm pela frente; humildes na aceitação da crítica justa; corajosos na defesa dos princípios da entidade quando os embates de idéias assim o exigirem; abertos à incorporação de novas análises, teses e propostas no plano educacional; visionários de um mundo mais humano e de uma sociedade justa e democrática. Em síntese: que tenhamos a capacidade, coragem e lucidez de juntos com todos os que fazem a entidade lutar para tornar cada vez mais brilhante o nome da ANPEd no cenário da educação nacional e internacional, contribuindo, desse modo, para ampliar a visibilidade da sua contribuição científica e política no campo educacional, inspirada nos ideais e compromissos com a democracia.

Aos colegas da ANPEd, integrantes dos grupos de trabalho, do fórum dos programas de pós-graduação, do Comitê Científico, um convite: contribuam com suas críticas, sugestões e propostas com esta direção, para que, de forma coletiva e transparente, possamos todos e todas reforçar o caráter acadêmico e a postura propositiva da entidade.

Por fim, ao trabalho, companheiros e companheiras, devolvendo, sob a forma da nossa produção científica e de nossa postura em defesa da coisa pública, o investimento que o país fez e faz na formação de gerações de intelectuais.

Concluo, convidando a todos a comemorar o processo democrático que se efetiva mais uma vez na 
entidade. Como disse nosso grande presidente Neidson Rodrigues: "A comemoração exige que se reúna. Comemorar é re-memorar e celebrar juntos a história que será contada, e que em cada re-memoração é recontada para que fique para sempre gravada na memória dos que participam da festa e da história”.

\section{Referências}

RODRIGUES, Neidson. Elogio à educação. São Paulo: Cortez, 1999. p.27.

SANTOS, Boaventura de Souza. A construção multicul-tural da igualdade e da diferença. In: CONGRESSO BRASILEIRO DE

SOCIOLOGIA, Rio de Janeiro: Instituto de Filosofia e Ciências Sociais da Universidade Federal do Rio de Janeiro, 4 a 6 de set. (Conferência), 1995.
MARCIAANGELADA SILVAAGUIAR, doutora em educação pela Universidade de São Paulo (USP) e professora no Programa de Pós-Graduação em Educação da Universidade Federal de Pernambuco (UFPE), é a atual presidente da Associação Nacional de Pós-Graduação e Pesquisa em Educação (ANPEd). Últimas publicações: Os institutos superiores da educação no Brasil: uma das faces da reforma educacional no Brasil (In: SGUISSARDI, V. (Org.). Educação superior: velhos e novos desafios. São Paulo: Xamã, 2000. p. 83-102); A formação dos profissionais da educação básica no curso de pedagogia (In: FERREIRA, N. S. C.; AGUIAR, M. A. da S. (Orgs.). Para onde vão a orientação e a supervisão educacional? São Paulo: Papirus, 2002. p. 107-122); em co-autoria com Marcia Maria de Oliveira Melo, Pedagogia e faculdades de educação: vicissitudes e possibilidades da formação pedagógica e docente nas IFES. (Educação \& Sociedade, Campinas: CEDES, v. 26, n. 92, p. 959982, 2005). Pesquisa em desenvolvimento: "Avaliação Processual do Programa ProJovem”. E-mail: marcia_angela@uol.com.br 